\title{
ESTRATÉGIA E ORGANIZAÇÃO: OS DILEMAS ORGANIZATIVOS DA NOVA ESQUERDA RADICAL
}

\section{Julio Cesar Gonçalves da Silva ${ }^{1}$}

Resumo: Este artigo procura relacionar teoricamente a questão organizativa com a estratégia política no contexto mundial do surgimento de uma nova esquerda radical. Defendendo uma perspectiva marxista que preserva um espaço autônomo para o campo da política, este trabalho explora as contribuições de Panebianco e Duverger para construir uma tipologia das organizações partidárias de esquerda. Procurando enfatizar as conseqüências de desenvolvimento estratégico dos diferentes tipos organizativos, argumenta-se que a nova esquerda radical precisa inovar em termos organizativos para escapar dos dilemas que a esquerda tradicional enfrentou até então.

Palavras-chave: partido político, organização, estratégia, socialismo.

Resumen: Este artículo trata de relacionar la teóricamente la estrategia política con la cuestión organizativa en el contexto global de la aparición de una nueva izquierda radical. Defendiendo una perspectiva marxista que conserva un espacio autónomo para el campo de la política, este trabajo explora las contribuciones de Panebianco y Duverger para construir una tipología de las organizaciones partidistas de la izquierda. Buscando hacer hincapié en las consecuencias de desarrollo estratégico de los diferentes tipos de organización, se argumenta que la nueva izquierda radical se necesita innovar organizativamente para escapar de los dilemas que la izquierda tradicional enfrentada hasta el momento.

Palabras-clave: Supremo partido político, organización, estrategia, socialismo

Abstract: This paper aim to relate organizational issue to political strategy in the global context of the emergence of a new radical left. Defending a Marxist perspective that preserves an autonomous space for the field of politics, this work explores the contributions of Panebianco and Duverger to construct a typology of left-wing partisan organizations. Looking for emphasize strategic development consequences of different organisational types, it is argued that the new radical left needs to innovate organizationally to escape the dilemmas that the traditional left faced so far.

Key-words: political party, organization, strategy, socialism

${ }^{1}$ Mestrando em Ciência Política pela Universidade Federal do Paraná. 


\section{INTRODUÇÃO}

Não se pode separar mecanicamente as questões políticas das questões de organização.

Lênin

Em um período de tempo relativamente curto surgiram diversas organizações partidárias na Europa situadas à esquerda dos partidos sociais democratas no espectro político: Aliança Verde-Vermelho na Dinamarca em 1989, Partido da Refundação Comunista na Itália em 1991, Bloco de Esquerda em Portugal no ano de 1999, Respect na Inglaterra em 2004, Syriza na Grécia em 2004, Die Linke na Alemanha em 2007, Novo Partido Anticapitalista na França em 2009, etc. Estes partidos passaram a formar um campo político que Daniel Bensaïd denomina de "nova esquerda radical”. Segundo o filósofo francês esse campo "surgiu no fim dos anos noventa com a renovação dos movimentos sociais e o auge do movimento alter-mundista" e sua "novidade reside em seu avanço eleitoral [...] que esboça uma tendência europeia (...), ainda frágil e desigual, segundo os distintos sistemas eleitorais" (Bensaïd, 2009).

A principal explicação para a emergência desse fenômeno está no contexto de crise política da esquerda tradicional. Os partidos comunistas identificados "com o 'campo socialista' e com a União Soviética, desapareceram ou viram sua base social se dissolver" enquanto a social-democracia "ao acompanhar e impulsionar as políticas liberais no marco dos tratados europeus, contribuiu ativamente para desmantelar o Estado de bem-estar social, no qual obtinha sua legitimidade" (Idem). A extrema esquerda existente não demonstrou força suficiente para preencher este espaço. De onde a emergência de partidos amplos que incluem uma grande diversidade de posições políticas à esquerda do social-liberalismo: reformistas, ex-stalinistas, militantes da extrema-esquerda, etc. Apesar das semelhanças, "a nova esquerda não constitui uma corrente homogênea (...). Inscreve-se mais bem num campo de forças polarizado, de um lado, pela resistência e pelos movimentos sociais, e do outro, pela tentação da respeitabilidade institucional” (Idem).

No Brasil, a experiência do Partido Socialismo e Liberdade (PSOL) aproximase desse quadro europeu: fundado em 2004, este partido reúne militantes de esquerda das mais distintas tradições desiludidos com os rumos do Partido dos Trabalhadores (PT) que chegou ao poder executivo em 2002 e com a experiência de isolamento da extrema-esquerda representada pelo Partido Socialista dos Trabalhadores Unificados. Organização pluralista e com melhor desempenho que o restante da esquerda radical 
do país ${ }^{2}$, a novidade representada pelo PSOL no sistema partidário brasileiro pode ser comparada ao surgimento da nova esquerda radical européia. E, assim como esta, o partido brasileiro vive o dilema entre a tentação institucional e a luta para afirmar-se como uma alternativa socialista.

Se o PSOL surgiu na cena política reivindicando os objetivos que o PT abandonou ao longo de sua trajetória, seria ele capaz de construir uma trajetória alternativa? O equacionamento dessa questão pode estar na compreensão do fato de que os partido são, "antes de tudo", organizações (Panebianco, 2005, p.3).

Este artigo visa, a partir do problema apresentado acima, pensar teoricamente a relação entre estratégia política e organização partidária. Em primeiro lugar, apresentamos a perspectiva marxista da qual resulta a problemática aqui estudada. Ao conceber a totalidade social como marcada pela discordância entre os tempos e as esferas ela torna possível dialogar com as contribuições da sociologia das organizações para investigar a lógica da representação partidária. Em seguida, apresentamos as principais contribuições de Panebianco para se pensar no problema do desenvolvimento organizativo de um modo não determinista nem reducionista. Logo após, demonstramos as contribuições de Duverger para investigar a estrutura partidária. Por fim, analisamos as relações entre os elementos analíticos apresentados anteriormente e a democracia como método de preservação dos interesses oficiais do partido e em oposição à lógica burocrática. Nas considerações finais, esboçamos os tipos ideais de organizações da esquerda partidária e as linhas políticas tendencialmente decorrentes destas para pensar em que sentido o PSOL e a nova esquerda radical pode se apresentar efetivamente como uma novidade.

\section{O PARTIDO COMO REPRESENTAÇÃO}

A tendência do marxismo vulgar sempre foi a de associar mecanicamente os partidos às classes sociais. A representação aparecia como um simples a priori produzindo simplificações da realidade política que geram a sua incompreensão. A redução dos partidos à simples representantes de interesses de classes torna incompreensível não somente os casos de afastamento do partido dos interesses classistas como o próprio processo de construção destes. Ao se conceber os interesses como simples produtos objetivos decorrentes de um determinado local ocupado pela classe social na estrutura econômica, perde-se de vista o processo histórico empírico de formação da classe em que os interesses são continuamente elaborados e modificados a

\footnotetext{
${ }^{2}$ Segundo Lacerda e Moura (2010), a atual esquerda radical brasileira legalizada é composta pelos seguintes partidos: Partido Comunista Brasileiro, Partido da Causa Operária, Partido Socialista dos Trabalhadores Unificados e Partido Socialismo e Liberdade.
} 
partir de experiências concretas (Thompson, 1987). Assim, acaba por caindo naquilo que Panebianco denominou de "preconceito sociológico" e que "consiste em considerar as atividades dos partidos (...) como o produto de 'demandas' dos grupos sociais por eles representados e, mais em geral, que os próprios partidos nada mais são do que a manifestação das divisões sociais" (Panebianco, 2005, p.4).

Contudo, a crítica do preconceito sociológico não atinge o marxismo como um todo. Em oposição às versões mais economicistas do marxismo, tem se desenvolvido uma forte vertente deste que trabalha com uma concepção de que o político é irredutível ao social. Assim, antes da representação ser dada como um a priori, é pensada justamente como o problema a ser investigado. Em um cuidadoso estudo das obras marxianas, Bensaïd (1999) demonstra que em todos os pontos da análise de Marx correspondência e discordância se combinam: na relação entre representantes e representados, na relação entre o político e econômico, na relação entre concepções do mundo e posição na estrutura social, etc. Negando a noção da totalidade social como um todo homogêneo, esta é concebida como cindida pela discordância entre os tempos e esferas que a constitui.

Esta "especificidade irredutível do político faz da caracterização social do Estado, dos partidos, a fortiori das teorias, um exercício eminentemente perigoso" (Bensaïd, 1999, p. 167). O grande problema, então, é articular duas dimensões contraditórias da mesma realidade: o político é e, ao mesmo tempo, não é expressão da divisão entre classes sociais.

A formação da classe trabalhadora como um sujeito coletivo com um projeto social autônomo em luta pela hegemonia social não é um dado natural da classe: "Se o proletariado é a classe potencialmente emancipadora, essa virtualidade não se realiza automaticamente" (Idem, p. 166). Devido à própria lógica de funcionamento do capital, o oprimido é "obrigado a resistir sob pena de ser pura e simplesmente esmagado" (Idem, 1999. p. 191). Porém, o desenvolvimento de uma consciência de classe revolucionária é constante destruído por fenômenos como o da reificação do Capital (Marx, 2002) e pela hegemonia burguesa no seio da sociedade civil (Gramsci, 2002). Assim, a consciência empírica da classe trabalhadora tenda a não ultrapassar os limites da concepção burguesa do mundo, isto é, tende a se adaptar à realidade capitalista existente. A formação de uma "consciência ético-política" nas classes subalternas, isto é, a consciência da necessidade destas se tornarem hegemônicas política, econômica e culturalmente, pelo contrário, é uma construção social em que o partido joga um papel chave (Gramsci, 2002). Por esta razão, o partido deve ser compreendido mais do que como uma simples expressão da divisão social de classes, mas como o próprio mecanismo que estabelece ou não a possibilidade desta se apresentar na cena política. 
O que nos remete para o nosso objeto com uma nova perspectiva: a nova esquerda radical se relaciona de que modo com esse processo de construção de uma consciência da classe trabalhadora? Ele tende a simplesmente se adaptar à consciência empírica ou tende a desenvolvê-la em um sentido ético-político? Ou ainda sua heteronomia de projeto em relação à consciência empírica de classe tende a condená-lo permanentemente a ocupar um espaço minoritário do espectro político-partidário?

Uma resposta para estas questões que evite ao mesmo tempo cair nos preconceitos sociológicos e teleológicos deve partir da compreensão da própria lógica do funcionamento interno dessas organizações. Em outras palavras, a questão do partido como representação nos conduz a uma interpretação do partido como organização.

\section{O PARTIDO COMO ORGANIZAÇÃO}

Um dos precursores da perspectiva dos partidos como organização, Michels (1982) direcionou suas observações teóricas justamente contra a percepção marxista do partido como representante de classe. Através de seus estudos sobre a socialdemocracia européia, sobretudo o Partido Social Democrata da Alemanha (SPD), ele observou que a lógica organizativa dos partidos operários trazia graves conseqüências políticas sobre os objetivos socialistas destes. Descrevendo o processo verificado de afastamento dos dirigentes do SPD da classe que estes afirmavam representar como sendo decorrente de uma lei inexorável de oligarquização das organizações, afirmou que os fins oficiais do partido tendem a ser substituídos pelos interesses de sobrevivência da própria organização da qual provém o poder dos dirigentes. Assim, a radicalidade de projeto de um partido socialista necessariamente seria deixada de lado no decorrer do processo evolutivo da organização, pois a preservação do aparelho implica em uma prática mais conservadora, na qual o partido procura se adaptar às instituições capitalistas que oficialmente deveria derrubar. Este processo de "substituição de fins" estaria inscrito na própria lógica do funcionamento do partido como organização: ao tornar-se "um fim em si mesmo, dando-se propósitos e interesses próprios, ele [o partido] se separa pouco a pouco da classe que representa" (Michels, 1982 p.234).

Apesar do seu caráter fortemente preditivo, a teoria de Michels apresenta-se em debilidade devido ao fato de encontrar-se fora de sintonia com a moderna epistemologia devido ao seu caráter fortemente determinista. Entretanto, esta perspectiva ganha um novo impulso quando este elemento é relativizado. 
Seguindo a perspectiva aberta por Michels, Panebianco (2205) afirma que todo partido está confrontado com os seguintes "dilemas organizativos" que ele deve equilibrar de algum modo ao longo de seu desenvolvimento: a) Modelo racional versus modelo do sistema natural; b) Incentivos coletivos versus incentivos seletivos; c) Adaptação ao ambiente versus predomínio; d) Liberdade de ação versus coerções organizativas.

Durante o seu processo de construção e consolidação, uma organização voluntária precisa distribuir incentivos para recrutar e manter seus membros na atividade. Esses incentivos podem ser distinguidos em três tipos: coletivos de identidade, seletivos materiais e seletivos de status. A "ideologia" partidária e os objetivos oficiais dela decorrente conferem identidade ao partido possibilitando que confluam para este os indivíduos que com ela se identificam (incentivos coletivos). Porém, como existem diversos tipos de obstáculos que se colocam para dedicação de todos em tempo integral à organização (seja de ordem familiar, financeira, etc., além, é claro, da incerteza de que estes objetivos serão atingidos e quanto à importância da sua ação individual), decorre uma descontinuidade da atividade da maior parte dos membros partidários. Assim, para garantir a continuidade da organização é necessário que o partido distribua recursos financeiros (incentivos seletivos materiais) e cargos de direção que conferem status e poder aos seus ocupantes (incentivos seletivos de status).

Esta distinção entre diferentes tipos de incentivos permitem evitar dois erros simétricos: o de considerar o partido como simples instrumento para realização de uma causa (modelo racional) ou como um mecanismo gerador de interesses próprios (sistema natural). O primeiro erro implica claramente no preconceito teleológico, o segundo leva a uma desconsideração do papel efetivo que os incentivos coletivos jogam na vida partidária. Se a "ideologia" partidária e os objetivos oficiais podem ser descritos muitas vezes fundamentalmente como uma simples máscara sob o qual se escondem interesses seletivos, não se pode ignorar que são eles que sustentam a própria identidade partidária que garante a ação política da base, algo fundamental para a existência dos chamados "partidos de massa".

Se todo partido é, ao mesmo tempo, um sistema de solidariedades e um sistema de interesses, o modo como cada partido soluciona este dilema dá origem a distintos desdobramentos e diversas tensões que irão envolver permanentemente a vida partidária. De onde cabe também aqui a crítica ao determinismo de Michels que afirma a tendência à oligarquização com a substituição de fins como uma lei de bronze. O que ocorre na verdade é que o dilema adaptação versus predomínio sobre o ambiente permanece como uma constante na vida dos partidos. Uma estratégia de predomínio muito acentuada pode colocar em risco a estabilidade partidária e, por conseguinte, o 
sistema de interesses que se assenta sobre o fluxo de incentivos seletivos. Pelo contrário, uma estratégia de adaptação muito acentuada visando garantir a maximização do fluxo dos incentivos seletivos pode produzir uma crise no partido enquanto sistema de solidariedade ao comprometer a própria identidade partidária. É exatamente por isso que apenas em casos extremos poderia se falar em substituição de fins, em condições normais o que ocorre é um processo de maior ou menor articulação dos fins tendo em vista o atendimento dos interesses que brotam no interior da organização. Por esta razão a tão propalada liberdade de ação dos líderes encontra um limite natural na própria coerção organizativa que lhes impõe uma busca pela manutenção de um equilíbrio estável entre os diversos dilemas organizativos.

Os distintos modos como os partidos políticos procuram equilibrar esses dilemas dão origem a distintas ordens organizativas. Estas tendem a se desenvolver ao longo do tempo em um processo que Panebianco denomina de institucionalização responsável pelas seguintes transformações:

a) Do sistema de solidariedade ao sistema de interesses, ou seja, de uma organização forjada para tentar alcançar os fins compartilhados por todos os participantes (conforme a perspectiva do modelo racional) a uma organização tendente a garantir a sobrevivência e a mediar objetivos e demandas heterogêneas (conforme a perspectiva do modelo do sistema natural).

b) Por conseguinte, a passagem de uma fase em que a organização é dominada por uma ideologia manifesta a uma fase em que a ideologia organizativa se torna latente. A essa transformação corresponde a uma modificação paralela no sistema de incentivos: de (predominantemente) coletivos de identidade a (predominantemente) seletivos - materiais sob a forma de retribuições regulares de um corpo burocrático. Tais transformações, por sua vez, acompanham e facilitam a passagem de uma fase dominada por uma participação de tipo "movimento social a uma fase dominada pela participação profissional.

c) De uma estratégia expansiva de predomínio sobre o ambiente a uma estratégia circunspecta de adaptação ao ambiente.

d) De uma fase de máxima liberdade de ação dos líderes (na definição dos objetivos, na seleção da base social, na formação da organização em geral) a uma fase de máxima compressão de liberdade de escolha e de manobra dos líderes (Panebianco, 2005, pp.318-319).

Se esse "tipo ideal" de desenvolvimento organizativo aproxima sua perspectiva com a de Michels, Panebianco observa, contudo, que este desenvolvimento pode ser perturbado por diversos fatores, entre os quais destacamos o modelo originário e as relações de poder no interior do partido cuja dinâmica é condicionada pelas mudanças ambientais.

Estas observações teóricas colocam em primeiro plano a perspectiva histórica e outros dois elementos que consideramos necessários adequá-los aos nossos objetivos. $\mathrm{O}$ primeiro elemento se refere à questão das relações de poder: se estas condicionam o 
desenvolvimento organizativo, a análise da estrutura partidária encontra complemento na investigação dos personagens que concentram a maior parte desse poder. O que nos conduz à importância de problematizar o conceito de "coalização dominante" de Panebianco. Uma das vantagens desse conceito é que ele permite observar que nem sempre o poder organizativo reside na direção. Não apenas reside algum grau de reciprocidade de poder em todos os níveis da organização partidária, como por vezes o centro do poder pode se localizar fora da direção tal como no corpo parlamentar ou em lideranças de organizações externas ao partido tal como os líderes das trade unions inglesas no Partido Trabalhista do início do século XX. Assim, o conceito de coalizão dominante aparece como sendo mais preciso do que o de direção política, pois ele permite dar conta do poder efetivo da organização, o qual na maioria dos casos difere do formal. Entretanto, esta noção pode conferir o mal-entendido de que sempre a direção efetiva do partido o domina, não estabelecendo nenhuma relação efetiva de representação. Por essa razão, optamos pela noção de coalizão dirigente.

O segundo elemento se refere à questão das relações da organização com o ambiente que condiciona estas relações de poder. É exatamente esse elemento que nos permite aproximar esta abordagem com a problemática marxista da luta de classes: nada nos impede de conceber este ambiente que condiciona a vida partidária como a contraditória sociedade capitalista com suas instituições que sustentam a hegemonia burguesa e na qual lutam para se desenvolver os elementos de contra-hegemonia das classes subalternas. O que não elimina, antes ressalta, que a representação de classe deve ser explicada em termos organizacionais, pois nesta perspectiva a estratégia partidária que fundamenta tipos diferenciados de representatividade classista não é apenas função do contato com as experiências concretas da luta de classes, mas também da "ordem organizativa".

Uma organização em que os interesses seletivos predominem sobre os coletivos necessariamente adotará estratégias de adaptação ambiental. Defender uma linha política que corresponda à consciência empírica da classe ao invés de desenvolvêla no sentido "ético político", certamente constitui o caminho mais fácil e seguro para conquistar cargos eletivos na institucionalidade burguesa e, deste modo, conquistar recursos financeiros que permitem a distribuição de incentivos seletivos materiais e de status. Uma organização que se consolide com a existência de mecanismos que garantam com certa eficácia a manutenção dos interesses seletivos subordinados aos interesses coletivos implica em uma linha política cujo sentido confere prioridade ao processo de construção da consciência "ético-política" em detrimento da conquista de recursos financeiros que permitam prover a crescente demanda pelos incentivos seletivos materiais. Ou seja, a conquista de mandatos eletivos pode ser apresentar mais 
como um meio do que um fim, o que evidentemente não elimina as tensões no sentido contrário. Justamente pelo fato do ambiente externo ser a sociedade capitalista é que uma organização socialista encontra-se constantemente sobre ameaça de desviar-se de seus objetivos enquanto uma organização que já completou o processo de substituição dos fins jamais pode ser recuperada para a luta socialista.

\section{A ORGANIZAÇÃO PARTIDÁRIA}

Apesar da importância destes elementos estabelecidos por Panebianco para se pensar o desenvolvimento partidário, consideramos necessário encontrar ferramentas mais precisas para se pensar na estrutura partidária. É exatamente por essa razão que os critérios clássicos estabelecidos por Duverger (1970) para a análise das estruturas partidárias se apresentam como um complemento necessário para nossa investigação.

Em primeiro lugar cabe desfazer aqui qualquer possível confusão entre a distinção partidos de massa e partidos de quadros estabelecida por Duverger com a polêmica partido de vanguarda e partido de massa entre Lênin e Rosa. Como a defesa leninena de partido de vanguarda implica em condições mais rigorosas para o recrutamento, especialmente devido às condições políticas de enfrentamento do absolutismo czarista, Rosa aparece como um contraponto com a defesa de um partido de massas aberto a toda classe. Ora, esta distinção nada tem a ver com as noções de Duverger.

Diferente da polêmica Rosa e Lênin em que o critério numérico é o utilizado para a distinção entre dois tipos de partido, Duverger observa que sua classificação dos partidos "não assenta em sua dimensão, no número de seus membros: não se trata de uma diferença de talhe, porém de estrutura" (Duverger, 1970, p.99). Os partidos de massa são aqueles que possuem nas classes populares a própria razão de existência, pois a realização dos seus objetivos implica no enquadramento destas em uma determinada direção. Além disto, estes partidos se caracterizam por certo grau de autonomia de classe, o que os leva a retirar as condições de sua sobrevivência não de recursos provenientes da classe dominante, mas da própria participação política e material de seus adeptos recrutados entre a massa. Os partidos de quadro, por sua vez, são aqueles que não dependem de uma adesão da massa para sua sobrevivência, mas da conquista de pessoas influentes e ilustres que permitam tanto por seu nome quanto pelo seu conhecimento técnico ou quantidade de dinheiro, ampliar a força eleitoral do partido. "Assim se explica que a distinção entre os partidos de quadros e os partidos de massa corresponde quase que do mesmo modo à da direita e da esquerda, dos 'partidos burgueses' e dos partidos 'proletários”' (Idem, p. 103). 
A fórmula do centralismo democrático, portanto, nos remete para um determinado tipo de partido de massa em que a função de enquadramento das classes populares é considerada mais importante do que o próprio tamanho numérico da organização. Sendo assim, por mais paradoxal que isto possa parecer, os partidos de vanguarda da extrema-esquerda se aproximam do tipo ideal de partidos de massa (embora nele não se encaixe plenamente). Inclusive, a fragilidade destes deve ser entendida justamente como fragilidade em conquistar a massa para seu projeto. Se o não compromisso por princípio com a classe antagônica inviabiliza qualquer outro tipo de crescimento, a "pequenez" dos partidos de extrema decorre do fato de que é pequena a parcela da massa conquistada para um projeto elaborado, ao menos no plano das intenções, para ela. Sendo assim, ao invés de partidos de quadros, estes são melhores entendidos a partir da noção da noção de seita uma vez que esta se remete justamente para postura intransigente e para o isolamento decorrente desta, elementos estes que caracterizam a vida destes pequenos partidos extremistas.

Sendo assim, ao contrário do que possa parecer, a classificação entre partido de massa e partido de quadros pouco nos diz em relação aos diversos tipos de partido de esquerda, sejam eles grandes ou pequenos, moderados ou radicais, democráticos ou burocratizados. O que nos remetem para outros critérios que permitam estabelecer outros tipos de distinções organizativas. Esses critérios podem ser encontrados na análise que o autor realiza dos arcabouços dos partidos, notadamente os diferentes tipos de elementos de base e os diferentes tipos de articulação geral da estrutura partidária.

Duverger distingue quatro tipos de elementos de base: o comitê, a seção, a célula e a milícia. Considerando que a milícia é típica dos partidos fascista e dos partidos anti-sistema em períodos e revolucionários (o que não se vislumbra em um horizonte próximo) nos deteremos a apresentar unicamente os três primeiros tipos, a começar pelo comitê. Este é típico dos partidos de quadros constituindo-se em um "agrupamento de pessoas importantes escolhidas em razão de sua influência" (Idem, p.53), não possuindo nenhum interesse em seu crescimento quantitativo. A atividade nos comitês se intensifica enormemente nos períodos eleitorais, tendo em vista que esta é sua função quase exclusiva. O grau de autonomia deles é, também por esta razão, extremamente elevado, o que confere um elevado grau de descentralização a estes partidos.

A seção, pelo contrário, é típica dos partidos socialistas de massa e sua preocupação essencial é com o crescimento quantitativo do partido procurando atrair para si o maior número de membros. Para manter esse contato com as massas, a organização das células ocorre tendo por base a divisão geográfica do país assim como 
os comitês. Nas cidades maiores pode ocorrer uma multiplicação das seções tendo por base a divisão por bairros ou regiões. Mas, de qualquer modo, permanecem como organizadoras de amplas massas, de onde decorre uma organização interior muito mais aperfeiçoada do que os comitês. Além disso, a seção faz parte do todo organizativo, o que lhe confere uma autonomia menor do que a dos comitês, os quais podem ser concebidos como uma vida isolada. Outra diferença importante é que, embora sua atividade se intensifique nos períodos eleitorais, a seção mantém um nível de atividade intermediário nos períodos de intervalo, pois sua função "não se trata apenas de tática eleitoral, mas também de educação política” (Idem, p. 59).

Se "as seções foram uma invenção socialista, as células são uma invenção comunista” (Idem, p.66). As células, embora se constituam como um elemento de organização das massas, se distinguem das seções por duas características fundamentais: o tamanho e a base do agrupamento. A organização da célula repousa, de um modo geral, em uma base profissional, o que reforça o caráter classista destes organismos. Não que não existam células organizadas em função da divisão territorial, mas estas guardam sempre uma divisão mais restrita (do bairro, da vila, da rua, etc.) e uma importância apenas secundária em termos numéricos comparativamente com as células organizadas por local de trabalho. Em termos de tamanho, a célula se caracteriza por organizar um número menor de partidários. Ao invés destes serem contados a centenas, se reduzem a poucas dezenas ou menos. A base profissional e a dimensão reduzida das células permitem uma maior integração de seus membros reforçando a solidariedade partidária. Assim, elas conseguem estabelecer um grau de atividade maior garantindo um funcionamento permanente que amplia ao máximo o número de atividades extra-institucionais, o que torna os partidos organizados em células algo muito distinto de uma máquina eleitoral.

As diferenças entre seção e célula podem ser bem explicitadas nessa passagem de Duverger que vale a penas citar longamente:

O comitê é essencialmente um organismo eleitoral e parlamentar, um instrumento adequado à conquista de eleitores e à pressão sobre os eleitos: permite organizar um escrutínio e pôr os cidadãos em contato com o seu deputado. Na seção, esse aspecto já se atenua sensìvelmente: suas reuniões permitem uma educação dos membros. Ela não procura apenas obter êxitos eleitorais, porém , proporcionar a seus adeptos uma formação política, e a constituir assim uma elite diretamente oriunda da massa e capaz de atuar em seu nome. Apesar de tudo, as preocupações eleitorais e parlamentares continuam predominantes. Ao contrário, na célula elas se tornam inteiramente secundárias. Pelo seu quadro e suas dimensões, a célula não passa de um instrumento adaptado à luta eleitoral: ela não coincide mais com uma circunscrição ou com uma subdivisão de circunscrição; é concebida pela ação no âmbito de uma empresa, e não pela participação num escrutínio político. Por certo, a agitação a cabo nas 
células pode servir a campanhas eleitorais, porém de uma forma indireta e difusa: aquelas devem ser conduzidas por outros organismos.

A escolha da célula como base de organização ocasiona, portanto, uma evolução profunda na própria noção de partido político. Em vez de um órgão destinado à conquista de sufrágio, à união dos eleitores e à manutenção do contato entre êles e os seus eleitores, êste se torna um instrumento de agitação, de propaganda, de enquadramento, e eventualmente de ação clandestina, para o qual as eleições e os debates parlamentares não passam de um meio de ação entre outros, e mesmo um meio secundário (Duverger, 1970, PP.70-71)

O modo como se articulam os diferentes organismos partidários a partir dos elementos de base dos partidos fornecem outros elementos fundamentais para a compreensão da estrutura partidária. A articulação das instâncias partidárias, de um modo geral, possui como base a divisão administrativa territorial do país. Essa articulação pode ser distinta entre forte e fraca (podendo ser ainda medido diversos graus de intensidade) de acordo com a maior ou menor precisão em que são estabelecidas estas ligações. Enquanto os partidos fracamente articulados se caracterizam por constituírem em um aglomerado incoerente de elementos de base reunidos em limites não definidos, os partidos de articulação forte regulamentam minuciosamente o modo de participação de cada um dos seus elementos na vida partidária global.

Se os partidos de esquerda diretos em geral se caracterizam por uma forte articulação, entretanto, os modos de ligação entre as instâncias partidárias variam de acordo com seu tipo. Duverger estabelece dois tipos de ligações verticais e horizontais: a primeira refere-se "a que une dois organismos um subordinado ao outro" e a segunda como "uma ligação entre dois organismos situados no mesmo nível” (Idem, p. 83). Evidentemente que em toda organização partidária prevalecem a ligações verticais, de tal modo que os partidos se distinguem apenas entre partidos de ligações mistas e partidos de ligações verticais, sendo estes últimos aqueles que não admitem nenhuma forma de ligação horizontal. Nos partidos de articulação forte as ligações horizontais tendem a guardar um caráter puramente excepcional ao ponto que nos partidos de articulação fraca estas ganham expressão máxima. De qualquer modo, é importante não confundir ligações verticais com centralização e ligações horizontais com descentralização embora sejam muitos os pontos de contatos entre elas: "Ligações verticais e ligações horizontais definem modalidades de coordenação dos elementos de base que compõe o partido; centralização e descentralização referem-se à repartição dos poderes entre os escalões de direção" (Idem, p. 88). Um partido é centralizado se o centro nacional tem o poder de decidir o conjunto da política partidária dando pouca autonomia para as direções locais. Um partido é descentralizado se as direções locais 
têm um amplo leque de poderes, mesmo que esteja proibida estaturiamente qualquer forma de articulação com outras instâncias da mesma esfera.

O grau de centralização, contudo, não deve se medida apenas no plano local, mas por quatro critérios distintos entre si: local, ideológica, social e federal. A centralização local é aquela característica da noção geral que se tem desse termo e se refere ao controle exercido sobre o centro nacional sobre as direções locais. A centralização ideológica, por sua vez, remete ao grau de autonomia que as tendências e frações possuem para funcionar como organizações separadas. A centralização social é uma questão que diz respeito aos somente aos partidos pluri-classistas que levam esta heterogeneidade no plano organizativo (ex. partidos confessionais) de tal modo que podem ser desconsiderada aqui. Já a questão da centralização federal consideramos útil agrupá-la junto com a descentralização local sob um novo rótulo. Desse modo, podemos reduzir os critérios para medir o grau de centralização dos partidos de esquerda à apenas dois: descentralização territorial e descentralização ideológica.

\section{ORGANIZAÇÃO E DEMOCRACIA PARTIDÁRIA}

Panebianco classifica os diversos militantes partidários em dois tipos ideais de acordo com o tipo de incentivo que predominantemente explica a sua ação: "crentes" (predominantemente coletivos) e "carreiristas" (predominantemente seletivos). Os primeiros descrevem, sobretudo, os militantes da base enquanto os segundo os funcionários liberados do partido (a burocracia), os parlamentares e seus assessores e, em menor ou maior medida, a direção partidária (contrapor à teoria leninista, nesta os militantes de vanguarda são justamente aqueles setores da direção que atuam predominantemente em função dos incentivos coletivos). O predomínio político dos militantes de tipo crente implica em uma maior permanência do partido enquanto "sistema de solidariedades" (modelo natural). O predomínio político dos militantes de tipo carreirista implica na transformação do partido em "sistema de interesse" (sistema natural). Ora, se os crentes se referem, sobretudo, à base partidária, a maior ou menor intensidade de reciprocidade de poder desta em relação à direção, à burocracia partidária, aos parlamentares e personalidades públicas, aparece como uma questão central para a preservação do sistema de solidariedades.

A relação entre democracia partidária e o tipo de articulação geral é complexa e não pode ser reduzida a uma fórmula evasiva geral. O caráter forte e fraco da articulação relaciona-se com a democracia apenas de modo negativo: uma articulação fraca certamente não é democrática, pois não permite nenhum controle efetivo da base sobre "os pequenos grupos oligárquicos" (Idem, p.79). Entretanto, o inverso não é 
verdadeiro, uma articulação forte pode significar tanto uma maior reciprocidade de poder da base como um meio de reforçar o controle da direção sobre ela. As ligações horizontais, por sua vez, de um modo geral se relacionam positivamente com a democracia, pois permitem que o contato entre os militantes se realize de forma direta, isto é, sem o controle da direção. Já as ligações verticais, constituem em "um meio admirável de manter a unidade e homogeneidade do partido" (Idem, p. 85). Embora concebidas para reduzir o pluralismo partidário, só estão em relação de total oposição com a democracia em condições em que ela se combina com um centralismo unidirecional do centro para a base. Afinal, essas ligações podem funcionar não apenas como um instrumento de manipulação da base pela direção nacional, mas também como um mecanismo eficaz de transmissão da vontade e opinião da base até o centro. Além disso, os ganhos em efetividade certamente superam em muito as perdas em termos de democracia.

O grau de centralização territorial, por sua vez, se relaciona positivamente com a democracia partidária por permitir o controle da maioria partidária sobre o conjunto da organização. Entretanto, para isto, é necessário que a base tenha efetivamente algum poder. $\mathrm{O}$ que não acontece quando esta centralização se combina com a centralização ideológica. Um partido monolítico, que proíbe a formação de tendências e frações ou obstaculiza o funcionamento destas, certamente se constitui em um partido em que a democracia inexiste ou não passa de uma mera fachada para o poder efetivo da direção partidária que funciona efetivamente com uma oligarquia fechada. Sem as garantias de pluralismo, o papel da base se limita a aceitar as decisões tomadas pela cúpula, uma vez que todo o seu poder se reduz a uma genérica possibilidade de desertar. Nessas condições até mesmo o poder de decidir entre essa ou aquela oligarquia que corresponda melhor aos seus interesses está efetivamente suprimido. Contraditoriamente, contudo, quando a descentralização ideológica é muito forte, não apenas o partido perde em efetividade como em democracia, pois o controle da base sobre o conjunto partidário é prejudicado em função da grande autonomia concedida às frações partidárias que, por esta razão, podem atuar contra a vontade da maioria.

A partir dos critérios apresentados acima, podemos considerar três tipos ideais de fórmulas organizativas nos partidos de esquerda: descentralização, centralismo burocrático e centralismo democrático.

O primeiro tipo se refere aos partidos socialistas. Aqui é preciso tomar um cuidado: mesmos estes partidos funcionam de forma centralizada, apenas em uma perspectiva comparativa que se limite aos partidos de esquerda inspirados (prática ou teoricamente) no centralismo democrático podemos dizer que os partidos socialistas 
são descentralizados, tanto no que se refere no plano territorial - os dirigentes locais possuem uma ampla gama de poderes - como, de um modo geral, no plano ideológico - as tendências e frações normalmente possuem um grau de autonomia muito acentuado. Isto inviabiliza quaisquer mecanismos de controle sobre o conjunto dos militantes, não criando nenhum obstáculo à tendência de adaptação a um ambiente hegemonizado pela burguesia.

Já a fórmula de centralismo democrático desde o início teve como objetivo "impedir que o oportunismo organizativo se transformasse em um oportunismo político” (Bianchi, 2009). É apenas através do centralismo democrático que a massa partidária pode exercer algum controle sobre os seus líderes e sobre as personalidades cuja fonte de poder provém de fontes externas ao partido, tais como os parlamentares e os dirigentes sindicais. Na fórmula lenineana, o centralismo aparece não como uma imposição de um centro à base em uma relação extremamente desigual, mas como condição mesma da democracia, para que exista uma reciprocidade de poder. Centralismo e democracia aparecem como duas faces da mesma moeda: "O que garante que a vontade da base partidária seja respeitada é a unidade do partido em torno da vontade de sua maioria. O que permite a unidade do partido, por outro lado, é a participação ativa da base partidária no processo de discussão e deliberação a respeito da estratégia e tática do partido" (Idem).

A distinção entre centralismo democrático e centralismo burocrático, entretanto, permanece como muito nebulosa. A dificuldade reside no fato de que os principais partidos situados neste ou naquele tipo são, na maioria dos casos, os mesmos: os partidos comunistas formados na década 20 em geral e o partido bolchevique em particular.

O próprio Duverger tende a assinalar a diferença entre o velho bolchevismo e o partido de Stalin ao observar que no partido bolchevique "os exemplos (...) permaneceram efetivamente coletivos; a discussão era real nos Comitês, as decisões eram verdadeiramente adotadas em comum" (Duverger, 1970, p. 216) e que, mesmo após a tomada do poder na Rússia, "subsistiram tendências por muito tempo" no interior do Partido Comunista. Além disto, descreve a passagem do velho bolchevismo para o stalinismo como um processo nem linear, nem inevitável: "a luta pela centralização ideológica foi muito longa, e se pode considerar que ela realmente não chegou ao fim senão em 1936" (Duverger, 1970, p.89). Porém Duverger não tira todas as conclusões deste fato, isto é, não distingue as duas fórmulas organizativas concebendo tanto uma quanto a outra sob o mesmo rótulo de centralismo democrático. De qualquer modo, o autor nos faz importantes indicações ao estabelecer uma distinção entre dois modelos de centralismo tendo por referência o contato com a base: o 
autocrático e democrático. "No centralismo autocrático, todas as decisões vêm do alto, e sua aplicação é controlada localmente por representantes da cúpula" (Duverger, 1970, p.92). Enquanto isso, o "centralismo democrático supõe (...) que se produzam discussões muito livres na base antes que a decisão seja adotada, para esclarecer o centro, mas que a disciplina mais rigorosa seja observada por todos depois que ocorre a decisão" (Idem, p.93). Embora o autor localize os partidos comunistas dentro do conceito de centralismo democrático e os fascistas dentro do conceito de centralismo autocrático, o desenvolvimento de sua argumentação apresenta indícios inequívocos de aproximação dos partidos comunistas do modelo de centralismo autocrático. Os diferentes papéis representados por Lênin e Stalin na liderança dos bolcheviques explicitam bem essa diferença: "O prestígio de Lênin era imenso, mas êle próprio procurava contê-lo e evitar o desenvolvimento do poder pessoal” (p.216), enquanto no período de Stalin, o chefe tal qual nos partidos fascista passa a ser "considerado em sua pessoa e não mais em sua função", gerando uma "personalização do poder" que se confunde "com uma verdadeira divinização do poder": "O chefe é onisciente, onipotente, infalível (...) toda vontade que dêle emana é a lei do partido" (Idem, pp. 217-218).

Para manter a distinção entre os partidos fascistas e os partidos comunistas evitamos classificá-los dentro do mesmo rótulo. Afinal de contas, nestes partidos a aparência democrática com todas suas implicações (entre as quais uma limitada reciprocidade de poder da base) ainda é resguardada, enquanto no primeiro prevalecem apenas as formas mais abertas de despotismo. De qualquer modo, a não utilização do termo centralismo democrático para se referir a estes partidos nos pareceu algo de importância primordial, de onde nossa opção pelo conceito de centralismo burocrático.

Apesar de centralismo democrático e burocrático se referirem a tipos ideais existe sempre algum grau de burocratização no centralismo democrático e vice-versa eles podem ser distinguidos empiricamente através dos critérios estabelecidos. No centralismo burocrático é admitida unicamente as ligações verticais, pois as ligações horizontais podem implicar em uma redução da coesão partidária unicamente em torno da vontade da oligarquia. No centralismo democrático a existência de ligações horizontais não é excluída por princípio, mas devido às condições de clandestinidade: a ausência destas se justifica em condições que é necessário diminuir ao máximo o contato entre os militantes para que a intervenção policial em um organismo não afete o conjunto do partido. Em condições de legalidade não existe razões para a sua proibição. Embora redutoras da coesão, os ganhos em termos democráticos fornecidos por estas ligações podem ser considerados suficientemente recompensadores para sua 
adoção até certo grau. Do mesmo modo, se a descentralização territorial normalmente não é admitida em nenhum dos casos, certo grau de descentralização ideológica é condição sine qua non para que o centralismo democrático possa ser efetivamente considerado como algo distinto.

Broué nos ajuda a esclarecer esse ponto ao destruir o mito de que o partido de Lênin seria algo monolítico. Segundo o autor, o princípio de centralismo democrático foi adotado pelo POSDR apenas em 1907 sendo resultado de uma exigência dos bolcheviques aos mencheviques para a reunificação do partido naquela ocasião. Neste momento, os bolcheviques passam a se constituir em uma facção no interior do partido, contando com uma organização própria bastante consolidada e, mesmo assim, permeada por um conjunto de tendências internas. A inclusão deste princípio tinha como objetivo, portanto, tão somente o estabelecimento da regra da submissão da minoria à maioria e não uma absoluta centralização ideológica do partido. Este exemplo demonstra que a fórmula do centralismo democrático é plenamente compatível até mesmo com a existência de frações e com a admissão de um pluralismo bastante elevado. O que ela procura garantir é tão somente a unidade na ação após o processo de tomada de decisões. Evidente que isto implica em aceitar a descentralização ideológica somente até o ponto em que ele passa a descaracterizar a própria noção geral de centralismo. Por esta razão que o grau de autonomia que goza cada fração e tendência no centralismo democrático é ao mesmo tempo muito mais elevado do que no centralismo burocrático (que sequer admite a existência destas) e muito inferior ao dos partidos socialistas descentralizados. Nestes últimos elas chegam a gozar do privilégio de atuar, quando possível, de acordo com seus próprios princípios mesmo quando estes estão em oposição com as decisões democraticamente adotadas pela coletividade partidária.

Além dos critérios estabelecidos por Duverger, consideramos de importância fundamental retornar ao modelo de Panebianco e acrescentar a observação da modalidade de sistema de incentivos predominante para a distinção destas duas fórmulas organizativas. No centralismo burocrático o poder dos líderes se sustenta no predomínio do sistema de incentivos seletivos, isto é, se apóia na burocracia partidária que através da submissão ao líder encontra possibilidades reais de ascensão profissional no interior da organização. A fórmula preconizada por Lenin, pelo contrário, se apóia primordialmente nos incentivos coletivos procurando estabelecer, para sua preservação, o máximo de reciprocidade de poder da base em termos de controle de todo o corpo partidário, aí inclusa a própria burocracia partidária.

A insistência na distinção entre essas duas fórmulas organizativas aqui é fundamental por duas razões: 1) para negar o unideterminismo presente em grande 
parte das obras que concebem o partido como organização que reafirmam a "lei de bronze da oligarquização" de Michels, (1982). Este tipo de abordagem, em muitos casos, se sustenta em um amalgama entre o velho bolchevismo e o stalinismo, fazendo perder de visão justamente aquilo que consideramos fundamental: não excluir de partida a existência de fórmulas organizativas que conduzem a outros destinos que não o da articulação/ substituição dos fins. 2) Apesar do processo de burocratização dos partidos comunistas, a fórmula do centralismo democrático sobreviveu nos partidos de extrema-esquerda, sobretudo nos de inspiração trotskista. O próprio Trótski julgava a si próprio e seus partidários como continuadores de Lênin no terreno organizativo, de onde a auto-designação de seus partidários como sendo bolcheviques-leninistas. Contudo, o longo período de isolamento do trotskismo não permitiu colocar a prova a eficácia desse modelo organizativo. Mais do que isto, justamente a manutenção desse isolamento coloca em questão esta eficácia nas democracias consolidadas. Panebianco, ao analisar a influência do tamanho do partido sobre sua organização, fez a seguinte observação que vale também citar longamente já que parece descrever plenamente a realidade vivida pela extrema esquerda:

Quando um partido nasce, normalmente os líderes devem praticar uma política expansiva, porque somente expandindo a dimensão organizativa o partido pode conseguir controlar recursos suficientes para garantir sua sobrevivência. Mas é possível (...) que os esforços dos líderes para expandir a organização sejam frustrados pela existência de um ambiente hostil (...) em que os recursos humanos, simbólicos e materiais de que o partido tem necessidade já estejam em poder de organizações preexistentes (...). Estando fechado o caminho para a institucionalização, todos os esforços dos líderes deverão se voltar à manutenção das características de 'sistema de solidariedades' da organização. Com efeito, nessas condições, o caminho alternativo da formação de um sistema de interesses, está por definição, impedido. Uma das conseqüências é que os objetivos organizativos, as metas ideológicas manifestas, não sofrem nenhum processo de 'articulação', de adaptação às exigências cotidianas. A única chance à disposição dos líderes para fazer com que a organização perdure ao máximo no tempo é tirar proveito de toda ocasião que surgir para perseguir efetivamente e até o fim os objetivos originários. Eis a razão para a forte coesão interna (característica do sistema de solidariedades) e para o estilo altamente ideológico da organização. Além disso, uma vez que a organização faz esforços contínuos para expandir-se mediante uma tentativa efetiva de atingir os objetivos originários, a hostilidade ambiental continua a crescer: o partido já estabelecido, cuja recém-nascida organização pretende subtrair parte do território de caça do domain, reage com o máximo de agressividade, contribuindo para isolar ulteriormente a pequena organização. A combinação de um ambiente hostil e uma incapacidade para superar o limite de sobrevivência gera, então, um círculo de sectarismo: quanto mais a organização é isolada e luta par garantir uma sobrevivência precária, mais deve opor-se frontalmente aos seus adversários políticos, e deles recebendo a mesma oposição (Panebianco, 2005, pp. 375-376). 
Por se basear no "sistema de solidariedades", a fórmula do centralismo democrático, ao que tudo indica, pode implicar em um isolamento ainda maior da organização quando o ambiente é extremamente hostil.

\section{CONSIDERAÇÕES FINAIS}

Em síntese, podemos chegar às seguintes observações analíticas. Um partido menos centralizado e baseado em seções tal como os partidos socialistas se revela mais tendencialmente adaptável à lógica política da sociedade burguesa. Um partido organizado pelo centralismo burocrático tende a tornar a organização em um fim em si mesma, o que gera uma linha política de maior adaptação ambiental em decorrência do fato de que uma estratégia pronunciadamente de predomínio significa um risco muito maior à estabilidade partidária. Um partido organizado por centralismo democrático, por sua vez, quando inserido em um ambiente hostil, pode gerar um círculo de sectarismo que o torna cada vez mais distante de realizar os seus objetivos, ainda que estes permaneçam inalterados. Ou seja, embora o afastamento dos objetivos oficiais seja um resultado em comum para estes distintos tipos organizativos, o caminho que leva a ele é muito diferente, pois se trata em diferentes riscos que ameaçam a vida partidária.

Quadro 1: Tipos ideais de partidos de esquerda

\begin{tabular}{|l|l|l|l|}
\hline Tipo & Partido Socialista & Partido Comunista & Extrema-esquerda \\
\hline Fórmula geral & Descentralização & $\begin{array}{l}\text { Centralismo } \\
\text { Burocrático }\end{array}$ & Centralismo democrático \\
\hline $\begin{array}{l}\text { Organismos de } \\
\text { Base }\end{array}$ & Seção & Células & Células \\
\hline Articulação geral & Forte & Forte & Forte \\
\hline Ligações & Mistas ou verticais & Verticais & Mistas ou verticais \\
\hline $\begin{array}{l}\text { Descentralização } \\
\text { territorial }\end{array}$ & Forte & Fraca & Fraca \\
\hline $\begin{array}{l}\text { Descentralização } \\
\text { ideológica }\end{array}$ & Forte & Fraca & Intermediária \\
\hline $\begin{array}{l}\text { Coalizão } \\
\text { dominante }\end{array}$ & $\begin{array}{l}\text { Compartilhada entre } \\
\text { parlamentares/ } \\
\text { personalidades }\end{array}$ & Comitê Executivo & Comitê executivo \\
\hline $\begin{array}{l}\text { Reciprocidade } \\
\text { de poder da base }\end{array}$ & Fraca & Fraca & Seletivos \\
\hline $\begin{array}{l}\text { Incentivos } \\
\text { predominantes }\end{array}$ & Seletivos & $\begin{array}{l}\text { Adaptação em } \\
\text { decorrência da } \\
\text { dinâmica de } \\
\text { oligarquização }\end{array}$ & $\begin{array}{l}\text { Círculo de sectarismo em } \\
\text { decorrência da não } \\
\text { ultrapassagem do limite de } \\
\text { sobrevivência }\end{array}$ \\
\hline $\begin{array}{l}\text { Linha política } \\
\text { tendencial }\end{array}$ & eleitoral & Coletivos \\
\hline
\end{tabular}

Fonte: Elaboração própria. 
Assim sendo, para construir algo diferente, a nova esquerda radical precisa escapar tanto da descentralização como do centralismo burocrático. Do mesmo modo, a fórmula do centralismo democrático não significa nenhuma garantia: a noção de partido amplo presente na nova esquerda radical possui como objetivo justamente superar o limite de sobrevivência que gera o círculo de sectarismo típico da extremaesquerda partidária. Por isso, estes partidos procuram estar aberto ao máximo para militantes de esquerda das distintas tradições, incluindo aí setores declaradamente reformistas. De onde a necessidade organizativa de preservar esse pluralismo.

Se o centralismo democrático é a forma política mais ou menos adequada para tentar manter o sistema de solidariedade e o pluralismo é a forma política encontrada para tentar superar o círculo de sectarismo, a nova esquerda radical precisa buscar de algum modo combinar estes dois elementos que, como vimos, guardam certo grau de contradição entre si. O modo e o grau eficiência desta combinação, entretanto, apenas podem ser verificados empiricamente em cada estudo de caso. Apesar desta supremacia da empiria, a combinação das ferramentas analíticas apresentadas acima nos permitiu construir o quadro analítico acima, o qual constitui em uma excelente ferramenta para "medir" até que ponto a nova esquerda radical consiste em uma efetiva novidade.

\section{REFERÊNCIAS BIBLIOGRÁFICAS}

BENSAÏD, D. Marx, o intempestivo. Grandezas e misérias de uma aventura crítica (séculos XIX e XX). Rio de Janeiro: Civilização Brasileira, 1999.

Emerge uma nova esquerda na Europa. Disponível em:

http://www.socialismo.org.br/portal/internacional/38-artigo/1255-emerge-uma-novaesquerda-na-europa. Acesso em 12 de maio de 2010.

BIANCHI, A. A organização como uma questão estratégica: passado e presente. Disponível em: www.pstu.org.br/teoria materia.asp?id=11420\&ida=29. Acesso em 20 de abril de 2010.

BROUÉ, P. O Partido Bolchevique: dos primeiros tempos à revolução de 17. Curitiba: Editora Pão e Rosas, 2005.

DUVERGER, M. Os partidos políticos. Rio de Janeiro: Zahar/UNB, 1970.

LACERDA, A.D. F. de \& MOURA, P. As razões da esquerda radical: eleições e organização partidária em um extremo ideológico. Anais do $7^{\circ}$ Encontro da Associação Brasileira de Ciência Política. Recife, ABCP, 2010.

GRAMSCI, A. 2002. Cadernos do Cárcere volume 3. Rio de Janeiro: Civilização Brasileira, 2002. 
LÉNINE, V. I.Obras Escolhidas em Três Tomos. Tomo I. Lisboa/Moscou:

"Avante!"/Progresso, 1977.

MARX, K. O Capital: Crítica da Economia Política, livro 1, volume 1. Ed. Civilização Brasileira. Rio de Janeiro, 2002.

MICHELS, R. Sociologia dos Partidos Políticos. Brasília, Editora Universidade de Brasília, 1982.

PANEBIANCO, A. Modelos de partido: organização e poder nos partidos políticos. São Paulo: Martins Fontes, 2005.

THOMPSON, E. P. A formação da classe operária inglesa: a árvore da liberdade. Volume 1. Rio de Janeiro: Paz e Terra, 1987. 